Article

\title{
Synthesis and Characterization of the Properties of Ceria Nanoparticles with Tunable Particle Size for the Decomposition of Chlorinated Pesticides
}

\author{
Kryštof Skrbek, Vilém Bartůněk, Michal Lojka, David Sedmidubský@iD and Ondřej Jankovský *(i) \\ Department of Inorganic Chemistry, Faculty of Chemical Technology, University of Chemistry and Technology, \\ Prague, Technická 5, 16628 Praha 6, Czech Republic; skrbekk@vscht.cz (K.S.); bartunev@vscht.cz (V.B.); \\ lojkam@vscht.cz (M.L.); sedmidub@vscht.cz (D.S.) \\ * Correspondence: ondrej.jankovsky@vscht.cz; Tel.: +420-220-442-002
}

Received: 13 July 2020; Accepted: 27 July 2020; Published: 29 July 2020

check for updates

Featured Application: Contamination of soil and water by halogenated hydrocarbons and other organic chemicals has become a serious issue. Organic chemicals are likely to exert acute lethal and chronic effects on sensitive fish, invertebrate or algae species. Organic chemicals endanger the health of freshwater ecosystems on the continental scale worldwide. These frightening problems need to be quickly and efficiently solved in order to restore balance in ecosystems. Ceria-based nanoobjects (e.g., nanoparticles, nanowires, nanosheets) have enormous potential to be used as catalysts for the decomposition of halogenated hydrocarbons. Ceria nanoobjects will be used in the future for the improvement of environmental conditions wherever the water or soil is contaminated by halogenated pesticides.

\begin{abstract}
Ceria nanoparticles are well known for their catalytic properties, which are commonly used in the automotive industry and other chemical branches. In this contribution, ceria nanoparticles were prepared by a simple precipitation reaction of cerium (IV) sulfate and ammonia. Such nanoparticles were very fine, with an approximate crystallite size of $2 \mathrm{~nm}$. Crystallite sizes of these nanoparticles were adjusted by controlled heating, showing different catalytic properties. After thermal treatment, the surface area and crystallite size of nanoparticles were also compared by means of XRD and a sorption analyzer utilizing Brunauer-Emmet-Teller (BET). Morphology was studied by SEM, high-resolution transmission electron microscopy (HR-TEM) and selected area electron diffraction (SAED). Thin layers of ceria nanoparticles on silica glass and alumina ceramic underlays were also prepared and studied by SEM and EDS to demonstrate the possibility of ceria immobilization using thermal treatment of raw nanoparticles. The catalytic activity of the nanoparticles was tested on a 2,4,6-trichlorophenol aqueous solution and compared by UV-VIS spectroscopy.
\end{abstract}

Keywords: ceria; nanoparticles; thermal treatment; crystallite size; catalysis; coatings

\section{Introduction}

Cerium (IV) dioxide (ceria) is one of the most common forms of cerium and it has a wide range of uses in applications mostly for its physical and mechanical properties. It is, for example, used as a polishing agent, an additive for heat-resisting alloys and in ceramics [1,2]. It is also added to thorium oxide gas lantern mantles. Without the presence of ceria, the flame would be practically colorless with minimal luminosity [3]. Another interesting application is its usage as a surrogate material for nuclear fuels [4].

On the other side, ceria nanoparticles are well known for their catalytic properties, which are widely used as an electrolyte material [5], in solid oxide fuel cells [6], in solar cells [7], for fuel 
oxidation [8], as automotive three-way catalysts to oxidize exhaust gases [9] and as part of composite materials [10]. Recently, lots of studies have also reported seeing the potential for usage of ceria nanoparticles in biotechnology, environmental chemistry and medicine [11,12].

Such a wide field of applications goes hand in hand with ceria nanoparticles' exceptional redox properties, which are mainly granted by the very fast redox-cycling between $(3+)$ and $(4+)$ states of cerium [13]. This cycling is caused by many oxygen vacancies that occur exclusively on the surface of nanoparticles, and the occurrence of these vacancies is not random [14]. The most stable vacancies are located at the (111), (110) and (310) crystal planes, whereas vacancies occurring in the bulk form are unstable [15]. The more the nanoparticle's crystallite size decreases, the more oxygen vacancies occur [16]. This undoubtedly has an impact on the nanoparticles' properties, which are therefore mainly controlled by the crystallite size of the nanoparticles and by the oxidation state of the cerium [17]. Precise control over the crystallite size of the ceria nanoparticles led us to the synthesis of a new, highly specifically working catalyst with unique properties [18].

Vast numbers of papers have been published referring to nanoparticle synthesis of ceria and other nanoparticles in general. The crystallite size of the nanoparticles can be modified both during and after synthesis. A dominant synthetic route in the case of the ceria nanoparticles is hydrothermal synthesis [19]. This method can be modified by e.g., use of different solvents [20] at different temperatures [21], by ultrasound [22], by use of various atmospheres [23] or by irradiation [24,25]. Methods having the most significant impact on the crystallite size of already synthesized nanoparticles are, in general, based on milling [26,27]. In this study, the modification of ceria nanoparticles' crystallite sizes was achieved using thermal treatment, and the as-prepared nanoparticles with different particle sizes were analyzed using a broad spectrum of analytic techniques. Because immobilization through thermal treatment of these materials is crucial for possible future applications, nanoparticles of various sizes were also examined for the catalytic decomposition of selected chlorinated phenols.

\section{Materials and Methods}

Ammonium hydroxide and cerium sulfate tetrahydrate were both of analytical grade purity (p.a.) and purchased from PENTA chemicals. 2,4,6-trichlorophenol of $98 \%$ purity was purchased from Sigma-Aldrich.

Ceria nanoparticles used for all experiments were prepared via a fast and simple precipitation method, where an aqueous solution of cerium (IV) sulfate and an ammonium water solution reacted [28]. Firstly, a saturated solution of cerium (IV) sulfate was prepared, which equaled the ratio of $6.5 \mathrm{~g}$ of cerium (IV) sulfate tetrahydrate to $10 \mathrm{~g}$ of distilled water. For the precipitation, a $25 \%$ aqueous ammonium solution was used, which was added dropwise until it reached a slightly alkaline environment. The formed suspension was washed multiple times with distilled water for the removal of ammonium sulfate byproduct. After having the nanoparticles washed, the centrifugation process was applied to remove the vast majority of the water and to hasten the drying process. After having the nanoparticles centrifuged, the nanoparticles were dried in a vacuum dryer at $35^{\circ} \mathrm{C}$ at $0.2 \mathrm{~atm}$.

Alumina crucibles were used for the thermal treatment experiment. Each crucible was filled with approximately $200 \mathrm{mg}$ of ceria nanoparticles. The heating of the samples was performed in a furnace with a static air atmosphere and a heating rate of $10^{\circ} \mathrm{C} / \mathrm{min}$. Target temperatures were as follows: $300{ }^{\circ} \mathrm{C}, 600^{\circ} \mathrm{C}, 900{ }^{\circ} \mathrm{C}$ and $1100^{\circ} \mathrm{C}$. When the final temperature was reached, each sample was taken out of the furnace and cooled rapidly to room temperature. Samples were termed according to their final temperatures as TT-300, TT-600, TT-900, and TT-1100. The nontreated sample (i.e., the reference sample) of the initial nanoparticles was termed TT-25.

Immobilization of ceria nanoparticles by the thermal treatment was demonstrated by attaching the same dose of non-treated ceria nanoparticles in the $5 \%$ ethanol dispersion to the roughened silica glass and alumina underlays respectively, with subsequent air drying. In order to create an immobilized layer, the samples were heated in a furnace with a static air atmosphere at a heating rate of $10^{\circ} \mathrm{C} / \mathrm{min}$ to the final temperature $1100^{\circ} \mathrm{C}$. 
The samples were then characterized by XRD, which was performed at room temperature using the Bruker 2D Phaser powder diffractometer with Bragg-Brentano parafocusing geometry, equipped with a Co lamp generating $\lambda=0.1789 \mathrm{~nm}$, and the setup used $\mathrm{U}=40 \mathrm{kV}, \mathrm{I}=40 \mathrm{~mA}$. The data were scanned over the angular range of $10-80^{\circ}(2 \theta)$ with a step size of $0.019^{\circ}(2 \theta)$. Panalytical X'Pert HighScore Plus software was used for XRD data analysis and for the calculations of nanoparticle sizes using the Debye-Scherrer calculator. The diffraction patterns were processed without background subtraction.

High-resolution transmission electron microscopy (HR-TEM) was performed using an EFTEM Jeol 2200 FS microscope (Jeol, Japan). A $200 \mathrm{kV}$ acceleration voltage was used for measurement. Sample preparation was attained by drop-casting the suspension $\left(1 \mathrm{mg} \mathrm{mL}^{-1}\right.$ in water) on a TEM grid (Cu, 200 mesh, Formvar/carbon) and drying it at $50^{\circ} \mathrm{C}$ for $12 \mathrm{~h}$. Structural characteristics were obtained from selected area electron diffraction (SAED).

The Brunauer-Emmett-Teller (BET) analysis of specific surfaces was performed using the NOVAtouch LX2 (Quantachrome Instruments) sorption analyzer. All samples were outgassed for $10 \mathrm{~h}$ at $100^{\circ} \mathrm{C}$ under a high vacuum. A nitrogen-cooled $(77 \mathrm{~K})$ detector was used for evaluation of the results using BET analysis and Kelvin equations. The Quantachrome software was used for the evaluation of measured data and for the determination of the surface area.

The morphology was investigated using SEM with an FEG electron source (a Tescan Lyra dual-beam microscope). To conduct the measurements, all samples were placed on carbon conductive tape. Each measurement was carried out using a $10 \mathrm{kV}$ electron beam. Elemental composition and mapping were measured by an EDS analyzer (X-MaxN) with a $20 \mathrm{~mm} 2$ SDD detector (Oxford instruments) and AZtecEnergy software. For the purposes of SEM and EDS measurements, the ceria layers on both the silicon glass and the alumina ceramics were coated by $5 \mathrm{~nm}$ of $\mathrm{Au}$.

Experiments assessing the catalytic activity of the nanoparticles were performed on a 2,4,6-trichlorophenol aqueous solution, which was measured with an Avantes AvaSpec UV-VIS spectroscope. For the experiment, $60 \mathrm{mg}$ of sample TT-25, TT-600 and TT- 1100 were put into three vials, and $10 \mathrm{~mL}$ of $9.5 \times 10^{-4} \mathrm{~mol} / \mathrm{L}$ concentrated 2,4,6-trichlorophenol (TCP) aqueous solution was then added to each. The light source provided a combination of both deuterium and halogen discharge tubes, which covered wavelengths from $180 \mathrm{~nm}$ to $880 \mathrm{~nm}$. All measurements were carried out in a $0.5 \mathrm{~cm}$ infrasil cuvette, and for the evaluation of data, Avasoft 8.2 software was used.

The thermal behavior was analyzed by simultaneous thermal analysis (STA). The DTA and TG curves were recorded simultaneously on a Linseis STA PT1600 apparatus at a heating rate of $10^{\circ} \mathrm{C} \cdot \mathrm{min}^{-1}$ in a dynamic air atmosphere $\left(50 \mathrm{~mL} \cdot \mathrm{min}^{-1}\right)$.

\section{Results and Discussion}

Dry ceria nanoparticles synthesized via the precipitation method can be seen in Figure 1a. Such nanoparticles were used as initial material for the thermal treatment method. These nanoparticles have a pale yellow color, which is distinctive for nanocrystalline cerium dioxide with a hydrated surface. Performance of the thermal treatment method led to both crystallite size changes and dehydration of the nanoparticles. Both of these effects had a major impact on the nanoparticles' color. The dehydration had a major impact at the beginning of the thermal treatment, which is documented in the STA measurements shown in Figure 1c. Based on the STA analysis, it was proved that nanocrystalline $\mathrm{CeO}_{2}$ contained approximately $17 \mathrm{wt} . \%$ of water. The dehydration process ended at approximately $300^{\circ} \mathrm{C}$, as can be seen from both the DTA and TG curves. Due to this fact, it is reasonable to prepare the first sample at $300{ }^{\circ} \mathrm{C}$ and the remaining samples at higher temperatures.

No color change could be observed when comparing the thermally treated samples; however, as is apparent from Figure 1, the nontreated sample was notably different from the heated ones. Due to the dehydration, the samples first turned brighter while, at higher temperatures, the effect of the crystallite growth turned the color to slightly pink. A summary of all prepared samples can be seen in Table 1. 
Table 1. Overview of prepared samples.

\begin{tabular}{cccccc}
\hline Temperature Used for Treatment & $\emptyset$ & $\mathbf{3 0 0}{ }^{\circ} \mathbf{C}$ & $\mathbf{6 0 0}{ }^{\circ} \mathbf{C}$ & $\mathbf{9 0 0}{ }^{\circ} \mathbf{C}$ & $\mathbf{1 1 0 0}{ }^{\circ} \mathbf{C}$ \\
\hline Sample name & TT-25 & TT-300 & TT-600 & TT-900 & TT-1100 \\
Average crystallite size & $20 \AA$ & $23 \AA$ & $35 \AA$ & $82 \AA$ & $357 \AA$ \\
\hline
\end{tabular}
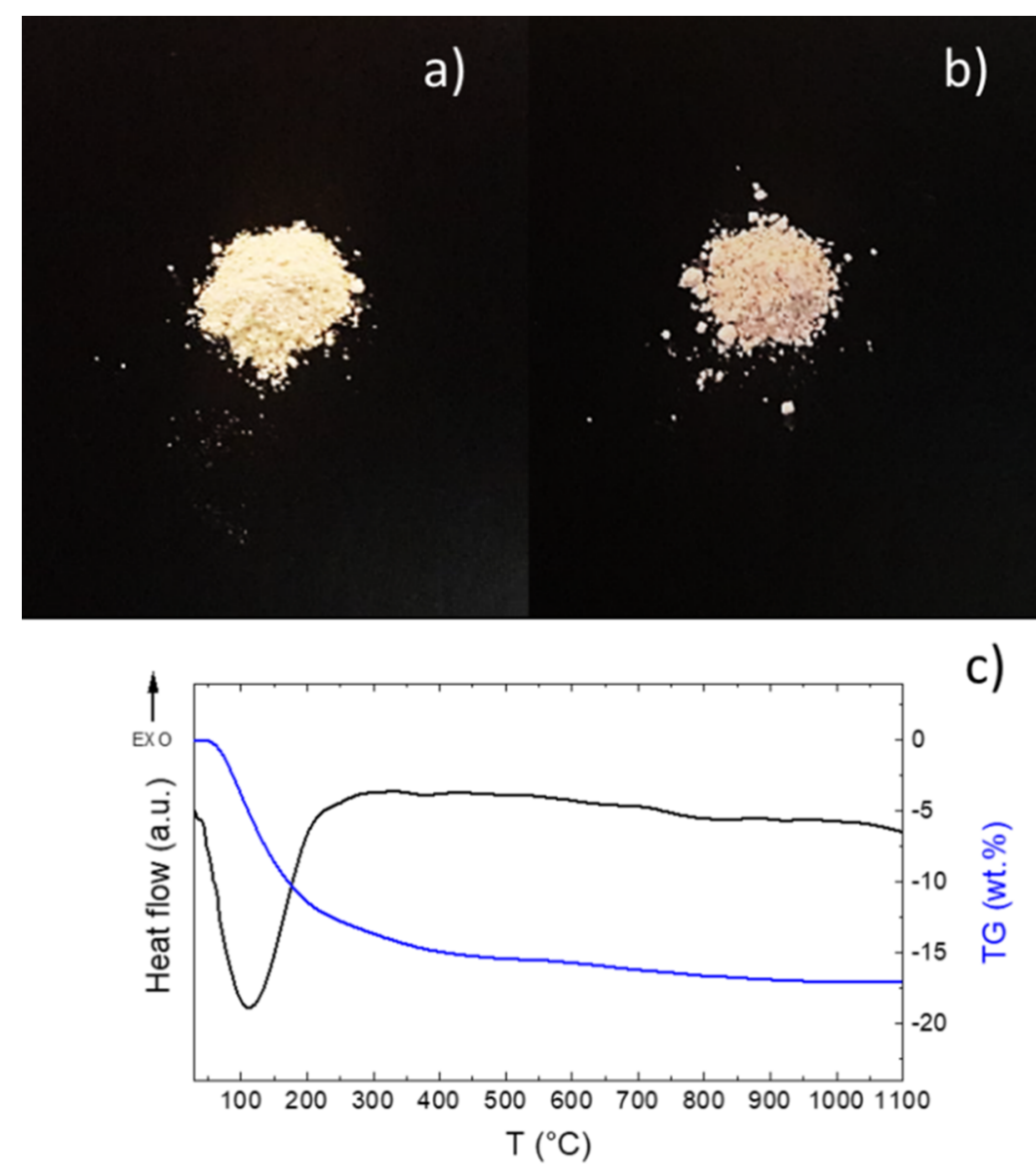

Figure 1. (a) Photography of ceria nanoparticles without thermal treating, (b) TT-1100 and (c) results of the simultaneous thermal analysis (STA) measurement.

The diffraction pattern of the precipitated ceria is shown in Figure 2a. The diffraction pattern corresponded with ICDD 04-013-9853 (cubic structure, space group Fm-3m) and the ceria was in the form of a fluorite structure, as expected. There was apparently no or only a low amount of the amorphous phase left after the processing of the precipitated sample (Figure 2a). According to the Scherrer equation, the crystallite size was approximately $18 \AA$ for the (111) crystallographic plane. Let us note that the approximate crystallite size was calculated as an average of the values obtained for the individual crystal planes. The diffraction on the (111) plane was the most significant and hence the most relevant. It is essential to mention that the calculated results can be affected by some error, especially for those crystallographic planes whose reflections overlapped. The diffractions belonging to the (220) and (311) planes were clearly recognizable, but no more reflections could be seen due to the very small particle sizes. For sample TT-300 (Figure 2b), there were no significant changes in comparison to the non-treated sample, TT-25. According to the estimation made by the Scherrer equation, the average crystallite size was around $22 \AA$. The average crystallite size of sample TT-600 (Figure 2c) reached $35 \AA$. We saw a new peak at approximately $2 \theta=70^{\circ}$, which was attributed to the (222) plane. The diffraction pattern of sample TT-900 is shown in Figure 2d. Here, the crystallite size value increased to $81 \AA$. The last sample, TT-1100, is shown in Figure 2e. The final size of the TT-1100 crystallites was $358 \AA$. 


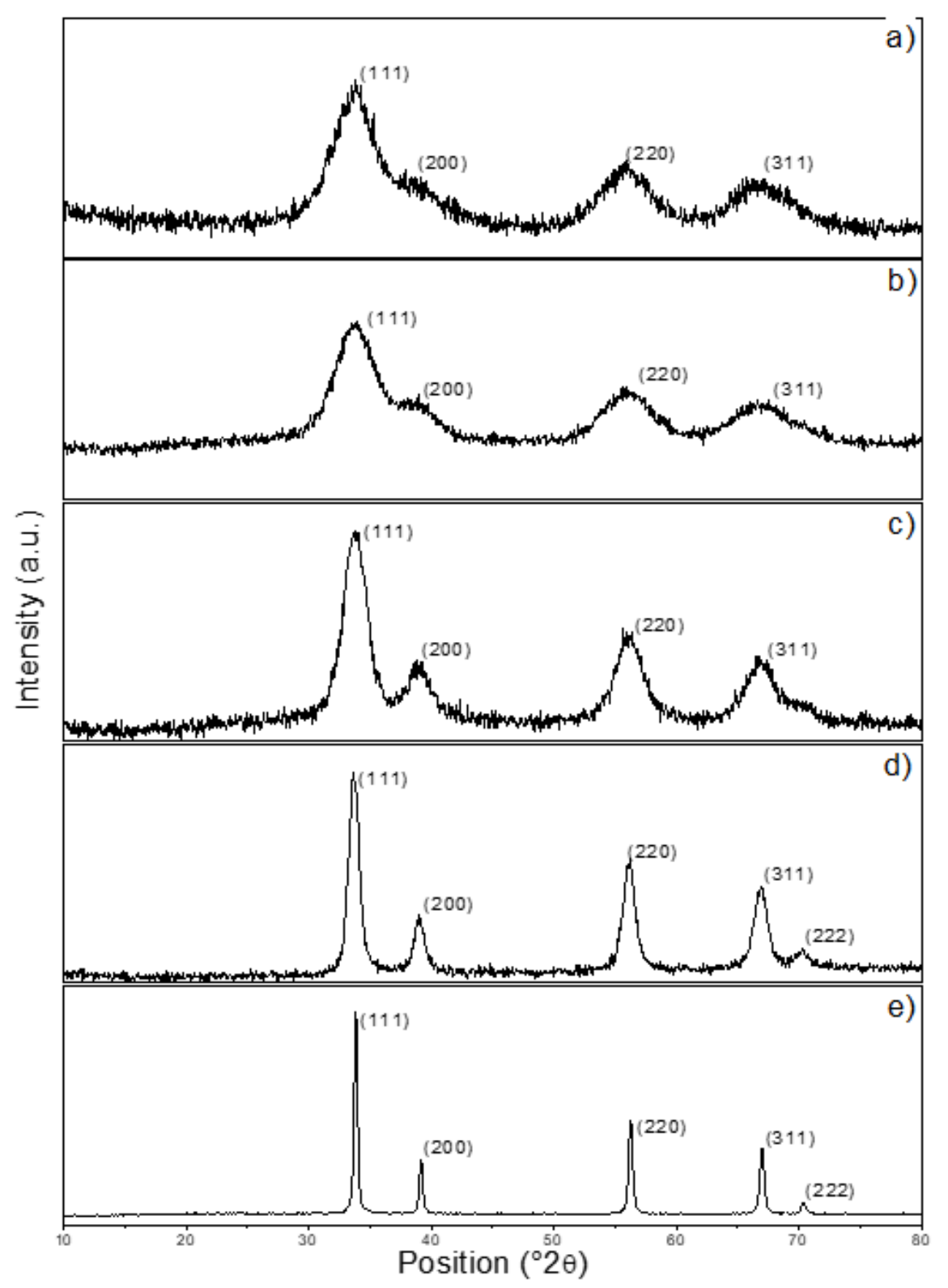

Figure 2. Diffraction patterns of ceria nanoparticles in (a) TT-25, (b) TT-300, (c) TT-600, (d) TT-900 and (e) TT-1100 samples.

The temperature dependence of the crystallite size is shown in Figure 3. As mentioned, the crystallite sizes were calculated from the Scherrer equation, making use of all crystal planes with the most intense signals: (220), (111) and (200). The average crystallite size was calculated and is also visualized in Figure 3. In this figure, the non-treated sample TT-25 is not included because its crystallite sizes were too small. 


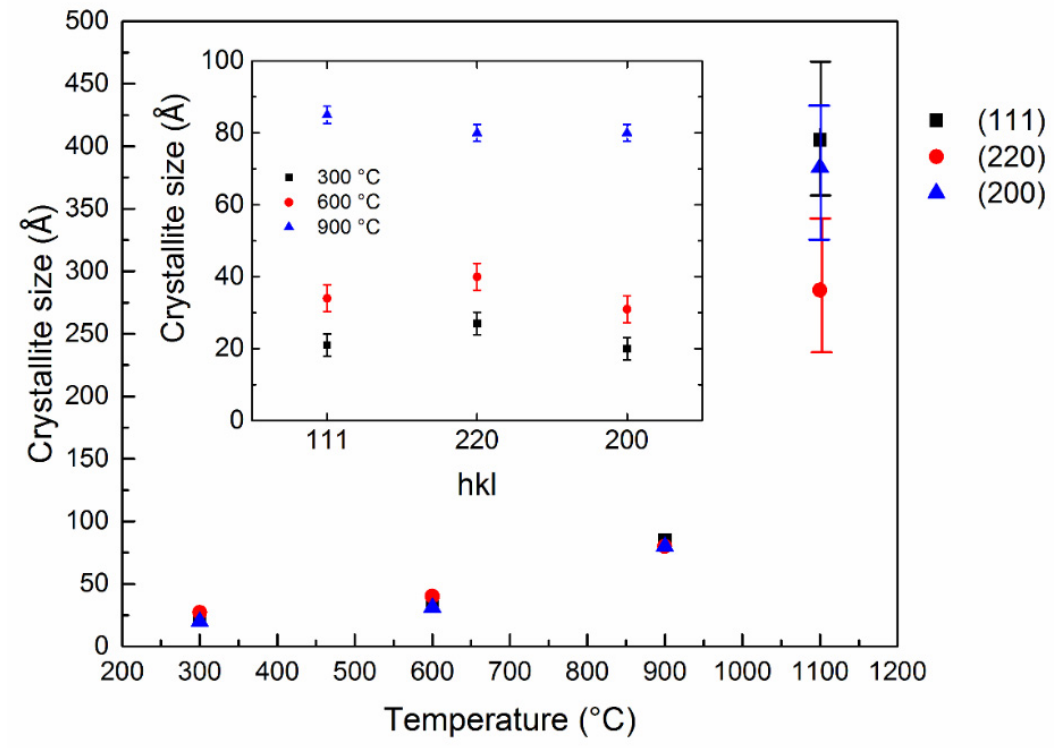

Figure 3. Crystallite sizes in directions of the (220), (111) and (200) crystal planes, and their average values.

The results of the SEM measurement can be seen in Figure 4. All pictures were captured with a magnification of 1300x. It is evident that the objects formed by the nontreated nanoparticles (Figure 4a) were finer and looser. With the increasing temperature, the nanoparticles conglomerated, forming bigger aggregates. However, it was difficult and almost impossible to determine the absolute size of the objects. Needless to say, the size of the formed objects was not uniform, but in general, when observing the treated samples, it was almost impossible to find such fine objects as in Figure 4a. Additionally, if we focus on the morphology of the TT-1100 sample shown in Figure 4e, we can see significant differences in comparison with the previous samples. Both of these effects had an impact on the surface area of the nanoparticles, which will be discussed later.

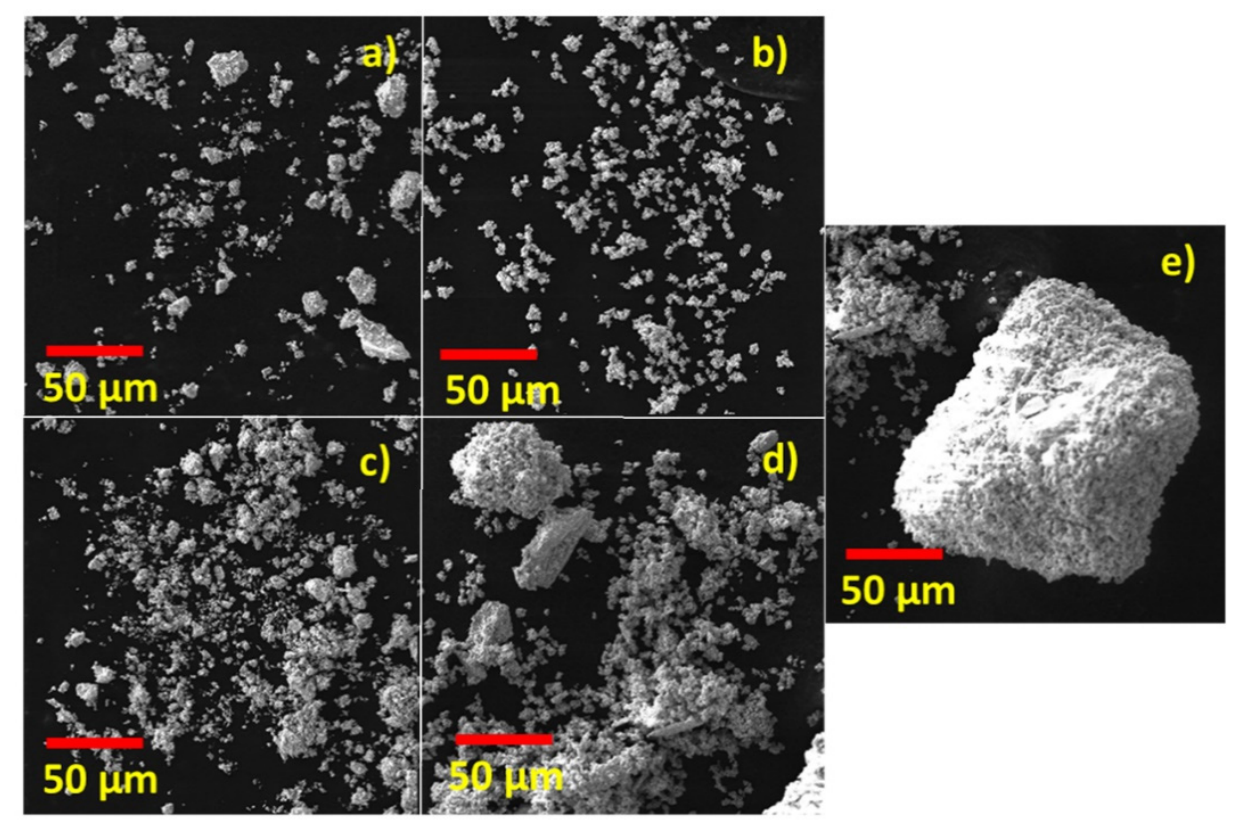

Figure 4. (a) SEM image of sample TT-25, (b) SEM image of sample TT-300, (c) SEM image of sample TT-600, (d) SEM image of sample TT-900 and (e) SEM image of sample TT-1100. 
To directly observe the size and morphology of the nanoparticles, a high-resolution transmission electron microscope (HR-TEM) was used. The measurements of selected samples TT-25 and TT-1100 can be seen in Figure 5, while TEM micrographs of all samples are shown in Figure S1 in Supporting Information. Increasing particle sizes with increasing temperatures were clearly visible. It is significant that the results of both the HR-TEM and SAED measurements were in agreement with the XRD measurements.

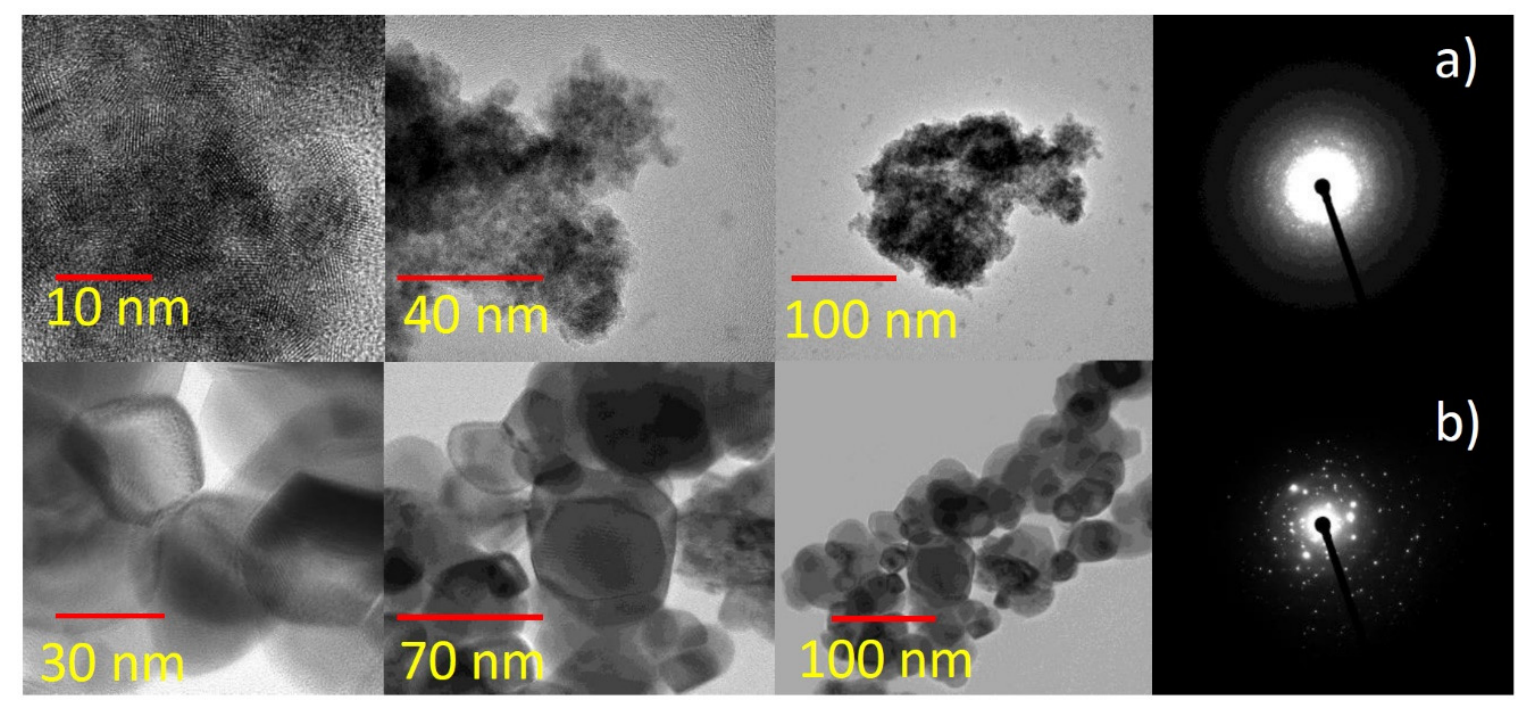

Figure 5. TEM micrographs and selected area electron diffraction (SAED) for samples (a) TT-25 and (b) TT-1100.

The BET analysis of the data obtained by a sorption analyzer was used for the nanoparticles' surface area determination. In relation to the catalytic activity of nanoparticles, the specific surface area was the most important quantity. The results of the measurements can be seen in Figure 6 . The most significant surface area change appeared for sample TT-300. This effect was a bit contrary to the X-ray diffraction measurements, where the changes in crystallite sizes between the low-temperature treated samples were only minimal. We believe that such a significant drop in surface area is due to dehydration of the surface and subsequent agglomeration or aggregation of ceria nanoparticles. After the first drop in surface area, we could see a quite linear decrease with the increasing temperature of the thermal treatment, corresponding to the crystallite size changes. Between samples TT-900 and TT-1100, we could see again a significant reduction in surface area. This nevertheless corresponded to the crystallite size change, which was unusually large in comparison with previous samples. If we focus on the absolute values of the surface area and crystallite sizes, we can see huge irregularities. These irregularities could be caused by the agglomeration and formation of the large clusters, which were observed by SEM. 


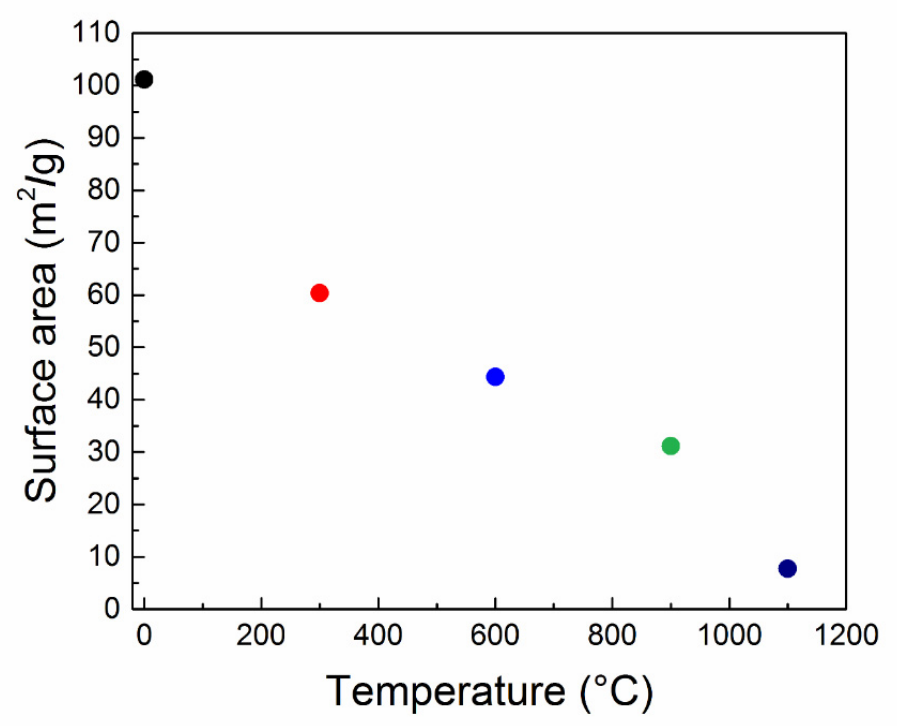

Figure 6. Results of the Brunauer-Emmett-Teller (BET) analysis, capturing the dependence of the surface area on the final temperature of the used thermal treatment.

Thin ceria layers prepared on alumina underlays (Figure 7a) and roughened silica glass (Figure 7b) were examined. The layers were sufficiently mechanically stable and, in the reverse horizontal position, no powder fell out of the samples. Similarly, the layers were resistant to laminar water flow. Nevertheless, for practical applications, other ingredients for better fixation of the ceria nanoparticles on the layer may be needed. Samples were also investigated by SEM and EDS. The morphology of the prepared layers with EDS maps of ceria can be seen. In both cases, the surface was relatively covered with similar complex ceria aggregates with apparently large surfaces. In the case of the alumina underlay, the cover was seemingly more homogenous, and this may indicate that the alumina surface is more convenient for the purpose of immobilization of catalytic ceria nano-surfaces than roughened silica glass. It is expected that the catalytic properties of ceria on alumina and silica underlays are about the same as the catalytic property of the nanoparticles synthesized at the same temperature, which is evaluated further in [29].

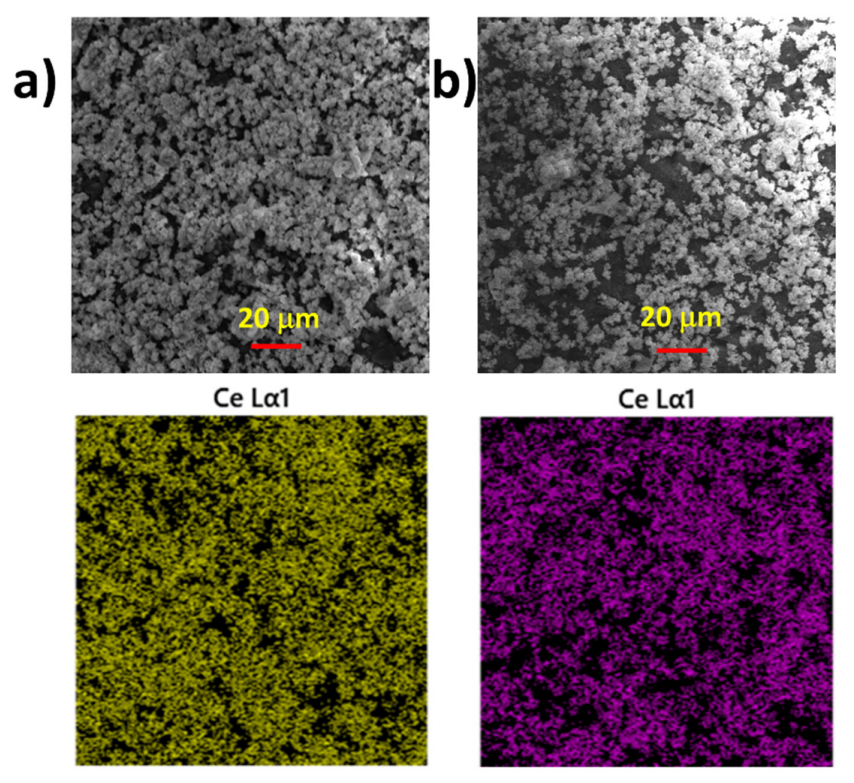

Figure 7. Thin ceria layers prepared on alumina underlays (a) and on roughened silica glass $(\mathbf{b})$ obtained by SEM and EDS. 
Synthesized nanoparticle fractions were evaluated on catalytic activity on model contaminant 2,4,6-TCP in a water environment. In order to rule out only the surface absorption effect, an experiment was carried out. A decreasing catalytic activity was expected to be observed with the growth of crystallite sizes. Therefore, because of their significant crystallite size differences, only the TT-25, TT-600 and TT-1100 samples were examined. For the UV-VIS measurement, each sample had to be centrifuged to get a liquid phase free from the nanoparticles. For this purpose, the SIGMA $2 \mathrm{k} 15$ centrifuge was used with the setup of 15,300 rpm. The first measurement took place $30 \mathrm{~min}$ after the experiment was set up, and then after 1, 5, 8, 12 and 14 days. After each measurement, the entire measured sample was returned to the centrifugation vial and placed for a sonic bath treatment, redispersing the separated nanoparticles to suppress their losses to a minimum. All samples were then stored in the dark under standard laboratory conditions. The results of the measurements can be seen in Figure 8. No detailed mechanism of the reaction was exanimated in this study, and it is described in the literature for Fenton-like catalysts $[30,31]$, where it is considered to be based on radical generation caused by the transition of oxidative states, in the case of $\mathrm{CeO}_{2}$ by $\mathrm{Ce}^{3+} / \mathrm{Ce}^{4+}$.

The molar amount of nanoparticles added to the system exceeded the molar amount of TCP by almost 72 times. According to our experience and measurements, such a surplus of nanoparticles should reliably shift the UV-VIS signal of TCP to lower energies, signaling the presence of the deprotonated form. As can be seen in Figure 8a, 30 min after the experiment started, the TT-25 sample signal showed an expected shift to higher wavelengths and increased its intensity. UV-VIS signals of all other samples also shifted to lower energies, but the absorbance decreased as the samples' surface areas diminished. The absorbance of the TT-25 sample remained unchanged during the entire experiment's duration, while all other samples' absorbances increased. As can be seen in Figure 8b, 14 days after the experiment had begun, the TT-600 sample showed a higher absorbance value, but still not as high as the TT-25 sample, while the TT-1100 sample still had the lowest absorbance value. The absolute concentration of TCP in the samples was not essential in the case of this experiment. This experiment just aimed to demonstrate that the surface area reduction of the used nanoparticles led to decreased catalytic activity. It is essential to say that we did not observe any unexpected reactions or by-products. We only observed a limited function of the treated nanoparticles, which means that the higher the temperature of nanoparticles' thermal treatment was, the higher the amount of catalyst that was needed to reach the same result as with the use of the non-treated ones. It has to be noted that the speed of the catalytic reaction was significantly slower than in the case of combined Fenton-like catalysts systems [30], but it was outweighed by the simplicity of the pure ceria system and by the possibility of using the high-temperature thermal method for preparation of advanced ceria-nanoparticle-based systems, which was proven by our study since the ceria nanoparticles treated at high temperatures were still active.
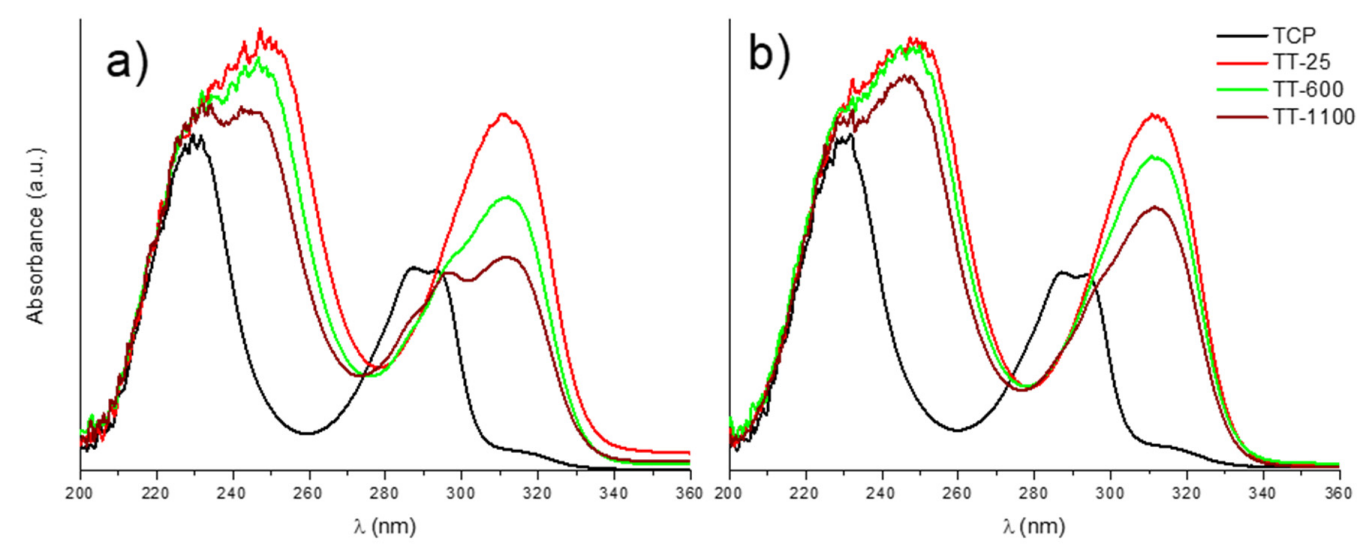

Figure 8. (a) UV-VIS spectrum measured $30 \mathrm{~min}$ after the experiment started. (b) UV-VIS spectrum measured 14 days after the experiment started. 


\section{Conclusions}

In this study, ultrafine nanoparticles of cerium dioxide were prepared by a simple precipitation method, where the approximate crystallite size of such prepared nanoparticles was around $18 \AA$. Application of the thermal treatment method to these nanoparticles led to apparent crystallite growth, which was clearly observed by XRD and HR-TEM, and the absolute crystallite size changes were calculated using the Debye-Scherrer formulae. As could have been predicted, the most significant crystallite growth occurred for temperatures higher than $900^{\circ} \mathrm{C}$. Moreover, there was a significant color change of the nanoparticles, depending on the nanoparticles' crystallite size changes and dehydration of their surfaces.

The results of the BET analysis showed a constant trend in the decrease of the nanoparticles' specific surface area; however, it did not correspond to the X-ray measurements. The surface area of the low-temperature-treated samples dropped very markedly, while at the same time, the crystallite sizes changes were only minimal. The most likely reason for this effect is the aggregate size change, which is very difficult to determine. In the case of this study, the SEM analysis was performed in order to unravel this trend, which showed the formation of various large objects. These definitely affect the surface area, but their size is impossible to determine precisely by SEM analyses. Thin layers of ceria on both glass and ceramic surfaces using the highest temperature of $1100{ }^{\circ} \mathrm{C}$ were prepared and exanimated to demonstrate the possibility of immobilization of ceria nanoparticles, which is important for possible catalysis applications.

Selected samples were tested for their catalytic properties, and all results appeared in accordance with the specific surface area. This means that the more the sample was thermally treated, the weaker and slower its catalytic reaction was. These results show promising potential for catalytic decomposition of chlorinated phenols, where the thermal treatment of the nanoparticles leads to reduced catalytic activity, but not to its vanishing. This might be useful for possible immobilization of such nanoparticles by the thermal processing of surfaces and, subsequently, for various environmental and industrial applications.

This contribution will be useful for advanced research in the catalytic decomposition of pesticide residues and for the processing of ceria-based ceramic composites, in which the temperature of sintering has to be carefully adjusted to avoid undesired crystallite growth.

Supplementary Materials: The Supplementary Material is available online at http://www.mdpi.com/2076-3417/ 10/15/5224/s1, Figure S1. Results of the High-resolution transmission electron microscopy and selected area diffraction for the samples (a) TT-25 (b) TT-300 (c) TT-600 (d) TT-900 (e) TT-1100.

Author Contributions: Conceptualization, V.B., O.J. and K.S.; methodology, V.B. and M.L.; investigation, K.S., D.S., M.L., V.B. and O.J.; writing-original draft, K.S., D.S., M.L. and O.J. All authors have read and agreed to the published version of the manuscript.

Funding: This work was supported by the Czech Science Foundation, grant number 20-03253S.

Conflicts of Interest: The authors declare no conflict of interest.

\section{References}

1. Rajeshkumar, S.; Naik, P. Synthesis and biomedical applications of Cerium oxide nanoparticles-A Review. Biotechnol. Rep. 2018, 17, 1-5. [CrossRef] [PubMed]

2. Khan, S.B.; Akhtar, K. Cerium Oxide: Applications and Attributes; IntechOpen: London, UK, 2019.

3. Aspinall, H.C. Chemistry of the f-Block Elements; Gordon \& Breach: London, UK, 2001.

4. Malakkal, L.; Prasad, A.; Oladimeji, D.; Jossou, E.; Ranasinghe, J.; Szpunar, B.; Bichler, L.; Szpunar, J. Atomistic and experimental study on thermal conductivity of bulk and porous cerium dioxide. Sci. Rep. 2019, 9, 6326. [CrossRef] [PubMed]

5. Steele, B.C.H. Behaviour of porous cathodes in high temperature fuel cells. Solid State Ion. 1997, 94, 239-248. [CrossRef] 
6. Singhal, S.C.; Dokiya, M.; Division, E.S.H.T.M.; Division, E.S.B.; Division, E.S.E.T.; Japan, S.S.O. Solid Oxide Fuel Cells VIII: (SOFC VIII): Proceedings of the International Symposium; Electrochemical Society: Pennington, NJ, USA, 2003.

7. Corma, A.; Atienzar, P.; Garcia, H.; Chane-Ching, J.Y. Hierarchically mesostructured doped $\mathrm{CeO}_{2}$ with potential for solar-cell use. Nat. Mater. 2004, 3, 394-397. [CrossRef] [PubMed]

8. Campbell, C.T.; Peden, C.H. Chemistry. Oxygen vacancies and catalysis on ceria surfaces. Science (N. Y.) 2005, 309, 713-714. [CrossRef] [PubMed]

9. Ivanov, V.K.; Shcherbakov, A.B.; Usatenko, A.V. Structure-sensitive properties and biomedical applications of nanodispersed cerium dioxide. Russ. Chem. Rev. 2009, 78, 855-871. [CrossRef]

10. Jankovský, O.; Antončík, F.; Hlásek, T.; Plecháček, V.; Sedmidubský, D.; Huber, Š.; Lojka, M.; Bartůněk, V. Synthesis and properties of $\mathrm{YBa} 2 \mathrm{Cu} 3 \mathrm{O} 7-\delta-\mathrm{Y} 2 \mathrm{Ba} 4 \mathrm{CuWO} 10.8$ superconducting composites. J. Eur. Ceram. Soc. 2018, 38, 2541-2546. [CrossRef]

11. Asati, A.; Santra, S.; Kaittanis, C.; Nath, S.; Perez, J.M. Oxidase-like activity of polymer-coated cerium oxide nanoparticles. Angew. Chem. (Int. Ed. Engl. ) 2009, 48, 2308-2312. [CrossRef]

12. Tarnuzzer, R.W.; Colon, J.; Patil, S.; Seal, S. Vacancy engineered ceria nanostructures for protection from radiation-induced cellular damage. Nano Lett. 2005, 5, 2573-2577. [CrossRef]

13. Dhall, A.; Self, W. Cerium Oxide Nanoparticles: A Brief Review of Their Synthesis Methods and Biomedical Applications. Antioxidants 2018, 7, 97. [CrossRef]

14. Jiang, Y.; Adams, J.B.; Schilfgaarde, M.V. Density-functional calculation of $\mathrm{CeO}_{2}$ surfaces and prediction of effects of oxygen partial pressure and temperature on stabilities. J. Chem. Phys. 2005, 123, 064701. [CrossRef]

15. Courtois, X.; Bion, N.; Marecot, P.; Duprez, D. The Role of Cerium-based Oxides used as Oxygen Storage Materials in DeNOx Catalysis Past and Present in DeNOx catalysis. In Molecular Modelling to Chemical Engineering; Granger, P., Parvulescu, V., Eds.; Elsevier: Amsterdam, The Netherlands, 2007.

16. Deshpande, S.; Patil, S.; Kuchibhatla, S.V.; Seal, S. Size dependency variation in lattice parameter and valency states in nanocrystalline cerium oxide. Appl. Phys. Lett. 2005, 87, 133113. [CrossRef]

17. Migani, A.; Vayssilov, G.N.; Bromley, S.T.; Illas, F.; Neyman, K.M. Greatly facilitated oxygen vacancy formation in ceria nanocrystallites. Chem. Commun. 2010, 46, 5936-5938. [CrossRef] [PubMed]

18. Sun, C.; Li, H.; Chen, L. Nanostructured ceria-based materials: Synthesis, properties, and applications. Energy Environ. Sci. 2012, 5, 8475-8505. [CrossRef]

19. Kaneko, K.; Inoke, K.; Freitag, B.; Hungria, A.B.; Midgley, P.A.; Hansen, T.W.; Zhang, J.; Ohara, S.; Adschiri, T.J.N.l. Structural and morphological characterization of cerium oxide nanocrystals prepared by hydrothermal synthesis. Nano Lett. 2007, 7, 421-425. [CrossRef]

20. Douglas, F.J.; MacLaren, D.A.; Murrie, M. A study of the role of the solvent during magnetite nanoparticle synthesis: Tuning size, shape and self-assembly. RSC Adv. 2012, 2, 8027-8035. [CrossRef]

21. Bartůněk, V.; Huber, Š.; Sedmidubský, D.; Sofer, Z.; Šimek, P.; Jankovský, O. CoO and $\mathrm{Co}_{3} \mathrm{O}_{4}$ nanoparticles with a tunable particle size. Ceram. Int. 2014, 40, 12591-12595. [CrossRef]

22. Badnore, A.U.; Chaudhari, A.P.; Patel, J.K.; Pandit, A.B. Effect of solvents on properties of the ultrasound assisted synthesized ceria nanoparticles and its performance as an adsorbent. Adv. Powder Technol. 2019, 30, 1058-1066. [CrossRef]

23. Jankovský, O.; Sedmidubský, D.; Šimek, P.; Sofer, Z.; Ulbrich, P.; Bartůněk, V. Synthesis of $\mathrm{MnO}_{1} \mathrm{Mn}_{2} \mathrm{O}_{3}$ and $\mathrm{Mn}_{3} \mathrm{O}_{4}$ nanocrystal clusters by thermal decomposition of manganese glycerolate. Ceram. Int. 2015, 41, 595-601. [CrossRef]

24. Del Angel, P.; Rodriguez-Hernandez, J.H.; Garcia-Borquez, A.; de la Fuente, J.A.M. Nucleation and growth of $\mathrm{Ni}^{0}$ nanoparticles and thin films by TEM electron irradiation. Catal. Today 2013, 212, 194-200. [CrossRef]

25. Wu, S.; Jiang, Y.; Hu, L.; Sun, J.; Wan, P.; Sun, L. Size-dependent crystalline fluctuation and growth mechanism of bismuth nanoparticles under electron beam irradiation. Nanoscale 2016, 8, 12282-12288. [CrossRef] [PubMed]

26. Debnath, D.; Lee, Y.; Geckeler, K.E. Biocompatible polymers as a tool for the synthesis of silver nanoparticles: Size tuning and in vitro cytotoxicity studies. Polym. Int. 2017, 66, 512-520. [CrossRef]

27. Sharma, G.; Dhawan, S.; Reed, N.; Chakrabarty, R.; Biswas, P. Collisional growth rate and correction factor for $\mathrm{TiO}_{2}$ nanoparticles at high temperatures in free molecular regime. J. Aerosol Sci. 2019, 127, 27-37. [CrossRef]

28. Bartunek, V.; Smrckova, O. Preparation and size control of cerium(IV) oxide ultrafine nanoparticles. Micro Nano Lett. 2010, 5, 222-224. [CrossRef] 
29. Skrbek, K.; Jankovský, O.; Sedmidubský, D.; Bartůněk, V. Flame aerosol transport method for assembling $\mathrm{CeO}_{2}-\mathrm{SiO}_{2}$ nanocomposites. Ceram. Int. 2020, 46, 5495-5499. [CrossRef]

30. Xu, L.; Wang, J. Degradation of 2,4,6-trichlorophenol using magnetic nanoscaled $\mathrm{Fe}_{3} \mathrm{O}_{4} / \mathrm{CeO}_{2}$ composite as a heterogeneous Fenton-like catalyst. Sep. Purif. Technol. 2015, 149, 255-264. [CrossRef]

31. Aneggi, E.; Trovarelli, A.; Goi, D. Degradation of phenol in wastewaters via heterogeneous Fenton-like $\mathrm{Ag} / \mathrm{CeO}_{2}$ catalyst. J. Environ. Chem. Eng. 2017, 5, 1159-1165. [CrossRef]

(c) (1)

(C) 2020 by the authors. Licensee MDPI, Basel, Switzerland. This article is an open access article distributed under the terms and conditions of the Creative Commons Attribution (CC BY) license (http://creativecommons.org/licenses/by/4.0/). 